\title{
Grand Challenges in Pharmaceutical Research Series: Ridding the Cold Chain for Biologics
}

\author{
Yihua Bruce Yu ${ }^{1,2}$ • Katharine T. Briggs ${ }^{1,2}$ • Marc B. Taraban ${ }^{1,2} \cdot$ Robert G. Brinson ${ }^{2} \cdot$ John P. Marino $^{2}$
}

Received: 6 January 2021 / Accepted: 12 January 2021

(C) The Author(s), under exclusive licence to Springer Science+Business Media, LLC part of Springer Nature 2021

\begin{abstract}
Biologics are complex pharmaceuticals that include formulated proteins, plasma products, vaccines, cell and gene therapy products, and biological tissues. These products are fragile and typically require cold chain for their delivery and storage. Delivering biologics, while maintaining the cold chain, whether standard $\left(2^{\circ} \mathrm{C}\right.$ to $8^{\circ} \mathrm{C}$ ) or deepfreeze (as cold as $-70^{\circ} \mathrm{C}$ ), requires extensive infrastructure that is expensive to build and maintain. This poses a huge challenge to equitable healthcare delivery, especially during a global pandemic. Even when the infrastructure is in place, breaches of the cold chain are common. Such breaches may damage the product, making therapeutics and vaccines ineffective or even harmful. Rather than strengthening the cold chain through building more infrastructure and imposing more stringent guidelines, we suggest that money and effort are best spent on making the cold chain unnecessary for biologics delivery and storage. To meet this grand challenge in pharmaceutical research, we highlight areas where innovations are needed in the design, formulation and biomanufacturing of biologics, including point-of-care manufacturing and inspection. These technological innovations would rely on fundamental advances in our understanding of biomolecules and cells.
\end{abstract}

KEY WORDS biologics - cold chain $\cdot$ COVID-19 - vaccine

\section{Yihua Bruce Yu byu@rx.umaryland.edu}

Bio- and Nano-Technology Center, University of Maryland, School of Pharmacy, Baltimore, Maryland 21201, USA

2 Institute for Bioscience and Biotechnology Research, National Institute of Standards and Technology and the University of Maryland, Rockville, Maryland 20850, USA
The COVID-19 pandemic brought an extremely important but largely hidden issue in healthcare delivery to the public view, the cold chain requirement for most biologic drugs and vaccines. In the United States, the New York Times (1) and the Washington Post (2), among other news outlets, as well as a scientific journal blog (3), have published articles highlighting the enormous challenge posed by the cold chain requirement in the fight against a global pandemic. The cold chain requirement is not new, and neither are the challenges posed by it. The COVID-19 pandemic simply put this issue under a spotlight for all to see.

Biologics are pharmaceutical products made using biological processes rather than chemical synthesis. Traditional biologics include therapeutic and diagnostic proteins (e.g., enzymes, hormones, and monoclonal antibodies), blood products and vaccines. Emerging biologics include genes, cells and tissue-based therapies. Many therapeutics and almost all prophylactics in development for the COVID-19 pandemic are biologics, such as monoclonal antibodies, convalescent plasma and vaccines.

Biologics are much more complex and much less stable than small molecule drugs. For small molecule drugs, the stability concern stems primarily from chemical degradation processes, such as oxidation and hydrolysis. Biologics also undergo chemical degradation but are more vulnerable than small molecule drugs because they often have multiple susceptible sites, such as cysteine residues for oxidation, and amide bonds for hydrolysis. Biologics, moreover, may not only suffer chemical degradation but also physical degradation, such as unfolding and aggregation. Whereas chemical degradation involves the disruption of covalent bonds, such as an amide bond or a disulfide bond, physical degradation involves the disruption of noncovalent interactions, such as a hydrogen bond, without altering covalent bonds. The activation energy barrier for the disruption of noncovalent interactions is typically much lower than that of the disruption of covalent bonds. Hence, physical degradation occurs more readily than chemical degradation. 
Because of the aforementioned stability differences, small molecule drugs can tolerate stresses commonly encountered during delivery, such as heat, freeze/thaw and agitation. As a result, small molecule drugs typically can be stored at room temperature, and temperature excursion to a reasonable extent can be tolerated. Further, homogeneous liquid preparations of small molecule drugs if accidentally frozen, can be thawed and the product still used in most cases.

In contrast, biologics are often susceptible to stresses commonly encountered during delivery. For this reason, most biologics, whether formulated as liquid preparations or lyophilized powders, are typically maintained within a narrow temperature range of $2^{\circ} \mathrm{C}$ to $8^{\circ} \mathrm{C}$ during delivery. Package inserts of biologic products typically instruct that temperature excursion outside of $2^{\circ} \mathrm{C}$ to $8^{\circ} \mathrm{C}$ is not allowed. Moreover, most liquid preparations, if accidentally frozen, should not be used after thawing.

Table I compares the storage conditions of two representative small molecule drugs and two representative biologics. The two small molecule drugs do not require refrigeration and are freeze-tolerant. In contrast, the two biologics require refrigeration but are freeze-intolerant, highlighting the fragility of biologic products.

An extreme form of cold chain requirement is for liquid preparations stored in a deepfreeze state, sometimes referred to as the ultracold chain. This occurs when the product could be damaged by the lyophilization process or when the regular cold chain of $2^{\circ} \mathrm{C}$ to $8^{\circ} \mathrm{C}$ provides insufficient protection of the product. One example of an approved biologic which requires storage between $-80^{\circ} \mathrm{C}$ to $-60^{\circ} \mathrm{C}$ is the anti-Ebola vaccine Ervebo, approved in 2019. Of the first four COVID-19 vaccine candidates in the US, two currently in Phase III clinical trials require the regular cold chain $\left(2^{\circ} \mathrm{C}\right.$ to $\left.8^{\circ} \mathrm{C}\right)$ and two that have been given the emergency use authorization by the FDA require the ultracold chain $\left(-20^{\circ} \mathrm{C}\right.$ for one and $-70^{\circ} \mathrm{C}$ for another $)(1,2)$.
Cold chain requires building extensive infrastructure and is very expensive to maintain. The complexity of the cold chain is illustrated in documents such as the GDC Vaccine Storage and Handling Toolkit (4) and the WHO pamphlet "The vaccine cold chain" (5). In fact, the updated CDC Toolkit has an addendum on COVID-19 vaccine storage and handling. For global healthcare delivery, the cold chain requirement is a huge barrier to biologic drug and vaccine accessibility and exacerbates healthcare inequity. This issue is amplified during a global pandemic when vaccines need to be simultaneously delivered to almost every corner of the world, with some regions that are frigidly cold, and others that are sweltering hot. Many places in the world do not have adequate infrastructure for the regular cold chain, let alone capability for deepfreeze at $-70^{\circ} \mathrm{C}$, which poses a steep logistical challenge even for industrialized countries (3).

Even with the requisite infrastructure in place, strict adherence to the cold chain requirement can be very difficult. In 2012, the Inspector General of the Department of Health and Human Services issued a report entitled "Vaccines for Children Program: Vulnerabilities in Vaccine Management" (6). The report identified multiple vulnerabilities in the distribution of vaccines for children (VFG) in the United States. Key findings include that $76 \%$ of 45 providers reviewed had exposed VFGs to inappropriate temperatures for at least 5 cumulative hours in a 2 -week period. All 45 providers had recorded temperatures that differed from independently measured temperatures during the 2-week period. And none of the 45 providers met the vaccine management requirements in all 10 categories (see Table I of (6)).

Another study, conducted by industry scientists in 2018, evaluated the impact of a CDC guidance on the number of Incorrect Product Storage Reports (IPSRs) for vaccines in the US (7). The guidance, originally issued in 2009 and updated in 2012, recommends the usage of digital data loggers to

Table I Storage Instructions (from Package Inserts) for Four Drug Products

\begin{tabular}{|c|c|c|c|}
\hline $\begin{array}{l}\text { Drug } \\
\text { Name }\end{array}$ & Drug Type & Description & Storage Instructions \\
\hline Gadavist & Small Molecule & $\begin{array}{l}\text { Contrast agent for magnetic } \\
\text { resonance imaging formulat- } \\
\text { ed as an aqueous solution }\end{array}$ & $\begin{array}{l}\text { Store at } 25^{\circ} \mathrm{C} \text {; excursions permitted to } 15^{\circ} \mathrm{C} \text { to } 30^{\circ} \mathrm{C} \text {. Should freezing occur, Gadavist should } \\
\text { be brought back to room temperature before use }\end{array}$ \\
\hline Taxol & Small Molecule & $\begin{array}{l}\text { Anti-cancer drug, formulated } \\
\text { as a viscous nonaqueous } \\
\text { solution }\end{array}$ & $\begin{array}{l}\text { Unopened vials of TAXOL (paclitaxel) Injection are stable until the date indicated on the } \\
\text { package when stored between } 20^{\circ} \mathrm{C} \text { and } 25^{\circ} \mathrm{C} \text {. Neither freezing nor refrigeration adversely } \\
\text { affects the stability of the product }\end{array}$ \\
\hline Humira & Biologic & $\begin{array}{l}\text { mAb drug for treating arthritis } \\
\text { formulated as an aqueous } \\
\text { solution }\end{array}$ & $\begin{array}{l}\text { HUMIRA must be refrigerated at } 2^{\circ} \mathrm{C} \text { to } 8^{\circ} \mathrm{C} \text {. DO NOT FREEZE. Do not use if frozen even if } \\
\text { it has been thawed }\end{array}$ \\
\hline Daptacel & Biologic & $\begin{array}{l}\text { Vaccine against diphtheria, teta- } \\
\text { nus and pertussis formulated } \\
\text { as an aqueous suspension }\end{array}$ & $\begin{array}{l}\text { DAPTACEL should be stored at } 2^{\circ} \text { to } 8^{\circ} \mathrm{C} \text {. DO NOT FREEZE. Product which have been } \\
\text { exposed to freezing should not be used }\end{array}$ \\
\hline
\end{tabular}


monitor vaccine storage temperature. In 2016, 12,993 IPSRs were filed, up from only one IPSR filing in 2004. This study showed that when the temperature was monitored closely, cold chain breaches were found to be common rather than rare events. Despite this report, it is worth noting not all cold chain breaches lead to less efficacious or even harmful biologic products; the extent of impact of cold change breaches varies and is not always known.

Unlike vaccines, which need to be administered by healthcare providers in clinics or pharmacies, many biologics for treating chronical conditions, such as diabetes and arthritis, are often delivered to a patient's home to enable self-injection. In such cases, strict adherence to the cold chain requirement is even less likely. Recent studies, using digital thermometers, found that the majority of diabetic and arthritic patients, around $80 \%$, expose their biologics to inappropriate temperatures $(8,9)$. A follow-up study indicates that the reasons are complex, including inconsistent guidelines, vague physician instructions, unreliability or even unavailability of household refrigerators, travel, and patient ignorance of storage requirements (10). Further, the mail order of drugs may exacerbate undetected cold chain breaches if robust monitoring procedures are not in place.

Cold chain breaches, if unnoticed before injection, could cause adverse drug events in patients. Spikes of pure red cell aplasia in Europe and Asia during 2000-2010 were attributed, at least in part, to cold chain breaches of Eprex, a glycoprotein drug for treating anemia $(11,12)$. Frozen and thawed insulin products have caused diabetic ketoacidosis in patients (13). Further, adverse events associated with vaccines can severely undermine vaccination programs, as illustrated by the Fluad case in Italy, where three vaccine-related deaths caused a $12 \%$ decrease in the vaccination rate in 2014 , followed by a $9.1 \%$ increase in the death rate in 2015 (14). In a world-wide vaccination program, it is very likely that some cold chain breaches will go unnoticed, and people may be vaccinated with spoiled vaccines that may be ineffective or even harmful. For example, some COVID-19 vaccine doses were administered to people before it was realized that they had been spoiled through an intentional breach of the cold chain (15).

On the other hand, cold chain breaches, if noticed before injection, may lead to massive wastage of drugs and vaccines, regardless of whether the breaches have actually damaged the products or not. In 2009, a shipment of insulin was exposed to $-0.1^{\circ} \mathrm{C}(10)$. Out of an abundance of caution, the entire shipment of insulin was destroyed, even though injectable drugs are typically made isotonic with human body fluids, which have a freezing temperature of $-0.52^{\circ} \mathrm{C}$. In this case, it was highly unlikely that the insulin products would have actually frozen at $-0.1^{\circ} \mathrm{C}$. Similar precaution is also practiced with vaccines, which leads to massive vaccine wastage. The WHO reports over $50 \%$ of vaccine wastage around the world, primarily caused by cold chain breaches, with freezing of vaccines being a bigger problem than heating (16). As the whole world population needs to be vaccinated against SARS-CoV-2 in a short period of time, strict adherence to cold chain is unrealistic and worsens both US and global healthcare inequity $(1,17)$, and vaccine wastage of $50 \%$ is intolerable.

\section{THE COLD CHAIN MUST GO}

As of now, cold chains are accepted as a fact of life and enormous efforts have been made to strengthen cold chains through better infrastructure and stricter guidelines. However, if cold chain breaches are not rare even in the US, improvement in infrastructure and stricter guidelines will only have limited impact on worldwide biologics delivery.

We suggest that the most effective way to deal with challenges posed by the cold chain is to make it no longer necessary for biologics delivery. Removing the cold chain requirement for biologics will greatly reduce healthcare costs, eliminate adverse events related to cold chain breaches, and improve patient quality of life (e.g., diabetic patients who travel). It will also abolish a significant factor in global healthcare inequity. In essence, we suggest money and effort are better spent on making the cold chain unnecessary for biologics than on strengthening it, similar to the idea that preventing COVID-19 is more efficient than treating it.

The removal of the cold chain requirement is much easier said than done. In our view, it constitutes a grand challenge for pharmaceutical research. We envision three potential approaches to meet this challenge.

The first approach would stabilize biologics through improved formulation, such as excipient innovation, protein engineering and lyophilization when suitable. Excipient innovation and protein engineering both have biological roots. Extremophiles and higher species often rely on osmolytes $(18,19)$ and/or certain protein structural features (20) to survive extreme cold or hot conditions. For example, overwintering insects can withstand large seasonal temperature fluctuations in their lifespan (21). This approach will likely involve the development of novel excipients that have not yet appeared in approved pharmaceutical products.

The second approach would engineer removal and renewal mechanisms into biologic products. This approach also has biological roots. In their native environments, proteins are constantly removed (through biodegradation) and renewed (through biosynthesis), with a half-life typically on the order of minutes to days. If degraded proteins/nucleic acids can be removed and renewed in biologics, then protection by the cold chain could be built into the products. Of course, the removal and renewal machinery itself should not require cold chain protection. Most likely, this approach will involve some form of drug/device combination, in the fashion of an artificial pancreas (22). 
The third approach would ditch the distribution process altogether. Instead of making biologics in a centralized location by drug companies, biologics would be made at the bedside or point-of-care by attending physicians and pharmacists, a process called magistral drug production $(23,24)$. Preliminary implementations of magistral drug production have been reported $(25,26)$. This approach requires not just making biologics, but also performing quality testing at the bedside. In this regard, fast and noninvasive analytical technologies such as water proton NMR (wNMR), may play a critical role (27).

All three approaches face significant technical, regulatory and economic challenges. Although achieving a cold chainfree distribution of all biologics will likely be years, if not decades, away, intermediate progress might not be that far off. For example, by making a biologic product, such as an mRNA vaccine, to withstand lyophilization, its cold chain requirement might be lessened from deepfreeze to regular cold chain (28). Also, technologies developed to rid the cold chain requirement may help in the interim to strengthen the cold chain. For example, rapid noninvasive analytical technologies may be used for quality testing in magistral drug production, but may also be used to determine before injection whether a vial of biologic drug or vaccine has indeed been damaged in the cold chain (27). Such bedside vial-specific quality data can pinpoint in a large shipment which vial should be thrown out, thereby ensuring biologic efficacy and safety, and which vial may still be used, thereby reducing biologic wastage. Such intermediate progress may help fight against the current COVID-19 pandemic.

With the end-goal clearly identified, i.e., to make cold chain unnecessary for biologics delivery, and the benefit clearly identified, i.e., an improved pandemic response and healthcare equity, we hope concerted efforts will be made by our community to meet this grand challenge in pharmaceutical research.

\section{DISCLAIMER}

These opinions, recommendations, findings, and conclusions do not necessarily reflect the views or policies of NIST or the United States Government.

\section{REFERENCES}

1. Gelles D. How to ship a vaccine at $-80^{\circ} \mathrm{C}$, and other obstacles in the Covid fight. New York Times Sept 18, 2020.

2. Johnson C. A single-shot coronavirus vaccine from Johnson \& Johnson will be tested in 60,000 people. Washington Post Sept 23, 2020.

3. Lowe D. Cold chain (and colder chain) distribution. Sci Transl Med. 2020; https://blogs.sciencemag.org/pipeline/archives/ 2020/08/31/cold-chain-and-colder-chain-distribution (
4. Centers for Disease Control and Prevention (CDG). Vaccine Storage and Handling Toolkit. 2020. https://www.cdc.gov/ vaccines/hcp/admin/storage/toolkit/storage-handling-toolkit.pdf

5. World Health Organization. Module 2: The Vaccine Cold Chain. Immun. Pract. A Pract. Guid. Heal. Staff, Geneva: WHO Press; 2015, p. 44 46. https://www.who.int/immunization/documents/ IIP2015_Module2.pdf

6. Levinson DR. Vaccines for children program: vulnerabilities in vaccine management (OEI-04-10-00430) Office of Inspector General, Dept of Health and Human Services 2012. https:// www.oig.hhs.gov/oei/reports/oei-04-10-00430.pdf

7. Wilson E, Zhu C, Galea S, Marko A, Victoria Urdaneta V, Straus W. Turning up the heat: effect of new vaccine for children's (VFC) program recommendations for use of temperature monitors upon incorrect product storage adverse event reporting. Vaccine. 2018;36:1516-20. https://doi.org/10.1016/j.vaccine.2017.10. 059 .

8. Braune K, Kraemer LA, Weinstein J, Zayani A, Heinemann L. Storage conditions of insulin in domestic refrigerators and when carried by patients: often outside recommended temperature range. Diabetes Technol Ther. 2019;21:238-44. https://doi.org/10. 1089/dia.2019.0046.

9. Santin G, da Silva MMM, Villarreal VA, Laste LDD, de Freitas ME, Betiol LER, et al. Home storage of biological medications administered to patients with rheumatic diseases. Adv Rheumatol. 2020;60:30. https://doi.org/10.1186/s42358-020-00131-x.

10. Heinemann L, Braune K, Garter A, Zayani A, Krämer LA. Insulin Storage: A Critical Reappraisal. J Diabetes Sci Technol. 2020. https://doi.org/10.1177/1932296819900258.

11. Macdougall IC, Roger SD, de Francisco A, Goldsmith DJA, Schellekens H, Ebbers H, et al. Antibody-mediated pure red cell aplasia in chronic kidney disease patients receiving erythropoiesisstimulating agents: new insights. Kidney Int. 2012;81:727-32. https://doi.org/10.1038/ki.2011.500.

12. Fotiou F, Aravind S, Wang P-P, Nerapusee O. Impact of illegal trade on the quality of epoetin alfa in Thailand. Clin Ther. 2009;31:336-46. https://doi.org/10.1016/j.clinthera.2009.02. 014.

13. Minuto N, Tambroni B, Vannati M, Emmanuele V, Russo C, Lorini $\mathrm{R}$, et al. Diabetic ketoacidosis caused by exposure of insulin to low temperature. Diabetes Technol Ther. 2010;12:745-6. https://doi.org/10.1089/dia.2010.0055.

14. Signorelli G, Odone A. Dramatic 2015 excess mortality in Italy: a 9.1\% increase that needs to be explained. Scand J Public Health. 2016;44:549-50. https://doi.org/10.1177/1403494816649833.

15. Stanley-Becker I, Salcedo A. Wisconsin pharmacist who 'intentionally' spoiled more than 500 vaccine doses is arrested, police say. Washington Post Dec 31, 2020.

16. World Health Organization. Monitoring vaccine wastage at country level. World Heal Organ Dep Immunization, Vaccines Biol. 2005; (V\&B):1-63.

17. Goldhill O. 'We're being left behind': rural hospitals can't afford ultra-cold freezers to store the leading Covid-19 vaccine. StatNews Nov 11, 2020.

18. Koštál V, Zahradníčková H, Šimek P, Zelený J. Multiple component system of sugars and polyols in the overwintering spruce bark beetle, Ips typographus. J Insect Physiol. 2007;53:580-6. https:// doi.org/10.1016/j.jinsphys.2007.02.009.

19. Walters KR Jr, Pan Q, Serianni AS, Duman JG. Cryoprotectant biosynthesis and the selective accumulation of threitol in the freezetolerant Alaskan beetle, Upis ceramboides. J Biol Chem. 2009;284: 16822-31. https://doi.org/10.1074/jbc.M109.013870.

20. Reed CJ, Lewis H, Trejo E, Winston V, Evilia C. Protein adaptations in Archaeal extremophiles. Archaea. 2013;2013:373275-14. https://doi.org/10.1155/2013/373275. 
21. Miller LK, Smith JS. Production of threitol and sorbitol by an adult insect: association with freezing tolerance. Nature. 1975;258:51920. https://doi.org/10.1038/258519a0.

22. U S Food and Drug Administration. What is the pancreas? What is an artificial pancreas device system? 2018. https://www.fda.gov/ medical-devices/artificial-pancreas-device-system/what-pancreaswhat-artificial-pancreas-device-system.

23. Schellekens H, Aldosari M, Talsma H, Mastrobattista E. Making individualized drugs a reality. Nat Biotechnol. 2017;35:507-13. https://doi.org/10.1038/nbt.3888.

24. Adiga R, Al-Adhami M, Andar A, Borhani S, Brown S, Burgenson $\mathrm{D}$, et al. Point-of-care production of therapeutic proteins of goodmanufacturing-practice quality. Nat Biomed Eng. 2018;2:675-86. https://doi.org/10.1038/s41551-018-0259-1.

25. Vaca González CP, Arteaga L, Delgado López NE. Magistral drug production in Colombia and other middle-income countries. Nat
Biotechnol. 2019;37:216-7. https://doi.org/10.1038/s41587-0190044-z.

26. Kalkman S, Arentshorst M, Hoekman J, Boon W, Uijtendaal E, van Thiel $\mathrm{G}$, et al. In-hospital production of medicines: preparing for disruption. Trends Biotechnol. 2020;38:1045-7. https://doi. org/10.1016/j.tibtech.2019.09.011.

27. Briggs KT, Taraban MB, Yu YB. Quality assurance at the pointof-care: noninvasively detecting vaccine freezing variability using water proton NMR. Vaccine. 2020;38:4853-60. https://doi.org/ 10.1016/j.vaccine.2020.05.049.

28. Kansteiner F. Amid cold chain blues, Pfizer looks to powder vaccine formula in 2021: report. FiercePharma Nov 11, 2020.

Publisher's Note Springer Nature remains neutral with regard to jurisdictional claims in published maps and institutional affiliations. 